COSTA RICO (Antón). - Historia da educación e da cultura en Galicia (Seculos IV-XX). Permanências e câmbios no contexto cultural e educativo europeo Préfaces de Xosé R. Barreiro Fernández et de Agustín Escolano Benito. Vigo : Edicións Xerais de Galicia, 2004. - 1246 p.

\title{
Antonio Novoa
}

\section{OpenEdition}

Journals

Édition électronique

URL : https://journals.openedition.org/histoire-education/1198

DOI : 10.4000/histoire-education. 1198

ISSN : 2102-5452

Éditeur

ENS Éditions

Édition imprimée

Date de publication : 1 janvier 2006

ISBN : 2-7342-1043-6

ISSN : 0221-6280

Référence électronique

Antonio Novoa, "COSTA RICO (Antón). - Historia da educación e da cultura en Galicia (Seculos IV-XX). Permanências e câmbios no contexto cultural e educativo europeo », Histoire de l'éducation [En ligne], 109 | 2006, mis en ligne le 02 avril 2012, consulté le 20 mai 2021. URL : http://journals.openedition.org/ histoire-education/1198 ; DOl : https://doi.org/10.4000/histoire-education.1198

Ce document a été généré automatiquement le 20 mai 2021.

(ㄷ) Tous droits réservés 


\section{COSTA RICO (Antón). - Historia da} educación e da cultura en Galicia (Seculos IV-XX). Permanências e câmbios no contexto cultural e educativo europeo

Préfaces de Xosé R. Barreiro Fernández et de Agustín Escolano Benito. Vigo : Edicións Xerais de Galicia, 2004. - 1246 p.

\section{Antonio Novoa}

\section{RÉFÉRENCE}

COSTA RICO (Antón). - Historia da educación e da cultura en Galicia (Seculos IV-XX).

Permanências e câmbios no contexto cultural e educativo europeo. / Préfaces de

Xosé R. Barreiro Fernández et de Agustín Escolano Benito. - Vigo : Edicións Xerais de

Galicia, 2004. - 1246 p.

1 Antón Costa Rico appartient à une génération qui a profondément renouvelé la recherche historique en éducation dans l'espace ibérique. Ayant soutenu sa thèse en 1982, il a publié une série d'ouvrages remarquables, toujours en galicien, dont on retiendra L'enseignement en Galice (1980), Écoles et maîtres (1989), La réforme de l'éducation (1986), L'histoire de l'enseignement dans le royaume de Galice (1995) et Sarmiento : vie et œuvre (2002). Le présent volume est le fruit de son laborieux travail de construction d'un ouvrage encyclopédique sur l'histoire de l'éducation et de la culture en Galice du IVe au XXe siècle. Il porte comme sous-titre : "Permanences et changements dans le contexte culturel et éducatif européen " et comporte 1246 pages, abondamment illustrées et remplies de tableaux, résumés, annexes et autres outils d'aide à la lecture, qui l'imposent comme un véritable monument. 
2 L'ampleur de l'entreprise historique d'A. Costa Rico semble faire écho au propos de René Rémond dans la préface au tome I de L'histoire générale de l'enseignement et de l'éducation en France, où il se déclare favorable à la constitution d'une catégorie spéciale, « la très longue durée », pour rendre compte de l'histoire de l'enseignement. Pourtant, A. Costa Rico, toujours soucieux de replacer les problématiques éducatives au sein des débats sociaux, politiques et culturels, adopte une perspective plutôt chronologique.

Dans l'introduction de l'ouvrage, Agustín Escolano Benito fait appel à la métaphore des "poupées russes" pour illustrer l'un des aspects les plus originaux de l'approche choisie: le dialogue entre trois histoires qui se croisent, se confondent et se confrontent - celles de la Galice, de l'Espagne et de l'Europe -, le regard se posant tantôt sur l'une, tantôt sur l'autre de ces « poupées ».

4 Mais Antón Costa Rico ne cache pas que son projet intellectuel se tisse autour de la mise en valeur du "passé éducatif » de la Galice, "beaucoup plus riche et complexe que ce qu'on a l'habitude de penser ». Et cela le conduit à édifier " une histoire qui prend en considération la Galice comme sujet historique et culturel, et les Galiciens comme des acteurs fondamentaux ». À cet égard, son entreprise rappelle le travail accompli par les historiens de la fin du XIXe siècle dans la construction d'un «passé » qui était partie essentielle de l'affirmation des nouvelles identités nationales. Mais ce programme est enrichi d'une compréhension fine des débats intellectuels et historiographiques contemporains, bien au-delà du cadre de la seule Galice. Nous nous trouvons donc devant un ouvrage d'une grande rigueur, qui révèle toute l'érudition de son auteur et constitue une référence fondamentale pour l'étude de l'éducation et de la culture en Galice. Ce genre de publication, fruit d'un travail démesuré - et, sans doute, passionné et d'une capacité intellectuelle peu fréquente, est rare dans le panorama historiographique actuel. 